\title{
Government as a platform, orchestration, and public value creation: The Italian case
}

\author{
Antonio Cordella, Andrea Paletti \\ Department of Management, London School of Economics and Political Science, UK
}

A B S TR A C T

\begin{abstract}
E-Government literature has discussed how the adoption of the Government as a Platform (GaaP) can help public administration to produce more efficient public services. However, since little attention has been given to the impact of GaaP on public value creation more research is needed to analyse whether the GaaP is effective to help the government to deliver public services that fulfil social expectations and, hence, public value. Indeed, efficiency does not guarantee public value. Besides efficiency, public value incorporates citizens' variegated expectations and needs that change over time and that are sometimes rival. For these reasons, the delivery of public value is often challenging for public agencies. The aim of this paper is to explain how the GaaP configuration can help public administration to deliver public value better. The paper finds that the modularity of the platform configuration and different ecosystems that support public agencies need to be orchestrated to support the effective creation of public value. The authors analyse the case of the Italian GaaP initiative to discuss the importance of the orchestration of the GaaP characteristics to improve the coordination among public agencies and enable the co-production of services with external actors, in order to deliver public value better. The findings show that the orchestration of the GaaP configuration characteristics can enable Italian public administration to deliver public value, but also that, if the GaaP is not properly orchestrated, it can constrain the creation of public value.
\end{abstract}

\section{Introduction}

Information and communication technologies (ICTs) have been the major enablers of public sector transformations. E-Government literature has discussed at length how ICTs have enabled public sector organisations to serve more and better public services. In recent years, there has been an increasing interest in the platform model ICTs enable, and on how this model drastically transforms the processes by which public services are produced, and the value these services deliver to citizens (Fishenden \& Thompson, 2013; Janssen, Charalabidis, \& Zuiderwijk, 2012; Linders, 2012; O'Reilly, 2011; Walravens \& Ballon, 2013). The concept of Government as a Platform (GaaP) envisages the transformation of the coordination among all national and local public agencies which compose public administration, from closed, structured, and formalised hierarchical relationships into open, flat, and unstructured relationships. Shared software, data, and services enable coordination among public agencies and open the public service production processes to actors who have been traditionally external to public administration. Key drivers for GaaP transformation projects are the efficiency gains the platform organisation offers (Janssen \& Estevez,
2013; Brown, Fishenden, Thompson, \& Venters, 2017; O'Reilly, 2011; Nitesh et al., 2013). O'Reilly's (2011) seminal work outlines the key factors that make the platform organisation in the public sector more efficient than other organisational configurations. Platform organisations increase public organisation efficiency because: 1) they enable the participation of external actors to co-produce public services, helping the organisation to deliver more value with fewer investments; 2) platforms build on modular structures based on stable core services to enable the development of third-party applications to support the evolution of service delivery and to reduce the complexity of the coordination of the actors who are involved in the production and delivery of these services; 3 ) platforms are easily accessible, and simplify the modification and creation of services. Moreover, the availability of open data, open standards, and open software that are often associated with public sector platform initiatives facilitates the collaboration among organisations and developers (McBride, Aavik, Toots, Kalvet, \& Krimmer, 2019; Nitesh et al., 2013; Sayogo \& Pardo, 2013; Sieber \& Johnson, 2015).

Although efficiency is a very important outcome GaaP initiatives deliver (O'Reilly, 2011; Janssen \& Estevez, 2013), it is essential not to 
neglect that the transformations GaaP projects convey might impact values, other than efficiency, that are delivered by public services. As every organisational configuration, the GaaP designs a unique way to produce and deliver public services which impact the public value it delivers (Moore, 1995).

So far, the GaaP literature has well discussed how the adoption of this new organisational configration by countries such as the UK, the USA, and Italy can increase the overall efficiency of the se rvice production and delivery (O'Reilly, 2011; Brown et al., 2017; Walravens \& Ballon, 2013; Janssen \& Estevez, 2013). However, citizens evaluate public services not only considering the efficiency of the production and delivery processes, but also considering other values associated with public services (Bannister \& Connolly, 2014; Cordella \& Bonina, 2012; Cordella \& Willcocks, 2010).

Therefore, public agencies that adopt the GaaP configuration with the goal to increase citizens' satisfaction should not only consider the efficiency of the se rvice pr oduction an d de livery pr ocesses bu the broader public value which this new way to produce and deliver services impacts.

This research sheds light on the impact that GaaP initiatives have on the creation of public value, and questions how the adoption of a platform configuration $\mathrm{c}$ an e nable $\mathrm{p}$ ublic a dministration $\mathrm{t}$ o deliver public value.

The paper builds on an explanatory case study of the 2017-2019 three-year plan for ICTs in public administration (herein the Italian GaaP reform), the Agenzia per l'Italia Digitale (AgID) has developed in conjunction with the Digital Transformation team - a temporary body the government constituted in 2016 to boost the development of Italian digital platforms. The findings reveal that the adoption of the platform configuration can support the Italian public administration to deliver public value better. However, the case also reveals that public services produced and served using the GaaP configuration can generate cross negative effects. $\mathrm{H}$ ence if $\mathrm{t}$ he $\mathrm{G}$ aaP c onfiguration is no $t$ adequately governed, it can negatively impact the creation of public value.

The paper proceeds as follows. First, it overviews the literature on public value and discusses how the GaaP impacts the creation of public value. Second, the paper presents a theoretical framework to frame the characteristics of the platform organisation that impact the creation of public value. Third, the paper introduces and discusses the case of the Italian GaaP initiative to understand how and why GaaP initiatives can help to produce and deliver better public value. The final section presents conclusions.

\section{The GaaP and the creation of public value}

A public value perspective (Benington \& Mark Moore, 2010; Moore, 1995) sees GaaP and the role of ICTs as enablers for a new organisational configuration to produce and deliver public services that enable the creation of public value. Moore's (1995) seminal contribution very well highlights the impact that the organisational configuration has on the creation and delivery of public value (Benington \& Mark Moore, 2010; Cordella, Paletti, \& Shaikh, 2018; Moore, 1995).

The strategic triangle suggests that public value creation is shaped by three main dimensions: the authorising environment, operational capacity, and public value outcomes (Fig. 1).

The authorising environment consists of the individual and collective values of the multiple stakeholders that engage in public value creation. It is the value domain within which public value is framed. The operational capacity is the organisational configuration and capacity which is used to create and deliver public value. The outcome of this process, such as public services and policies, are valued by citizens on the ground of their preferences: what the authorising environment frames and defines.

In this work, the authors primarily focus on operational capability and discuss how it can (or cannot) deliver public value effectively.

Therefore, public value can provide a valuable perspective to better
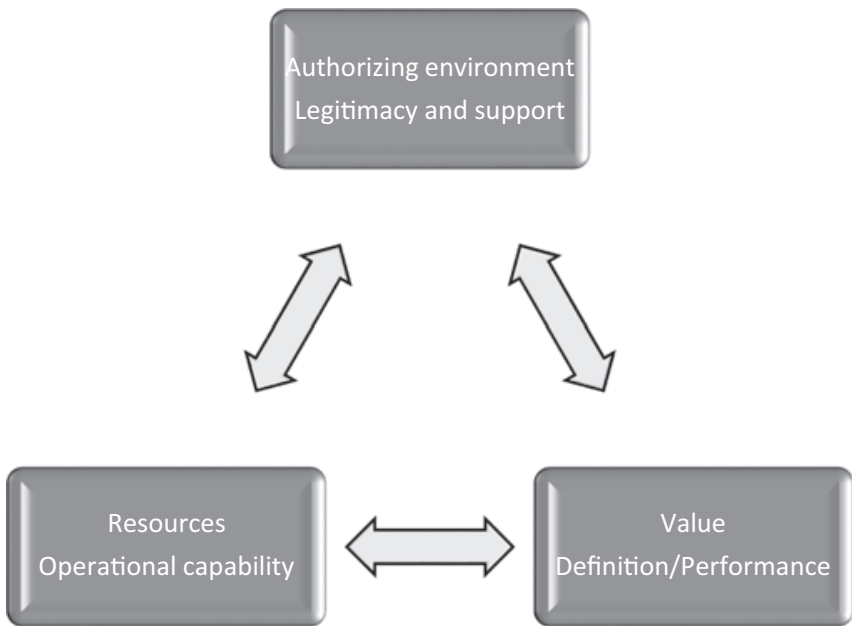

Fig. 1. Strategic triangle of public value creation (Moore, 1995).

understand the impacts of GaaP configurations on the creation and delivery of public service.

While Moore's strategic triangle is useful to understand the different dimensions that affect value creation, the theory of public value embraces a complex set of ideas and concepts which do not necessarily share the same explanations of what is needed to create value (Morrell, 2009). Accordingly, the literature (Alford \& O'Flynn, 2009; Dahl \& Soss, 2014) offers two different explanations of the creation of public value. On the one hand, the creation of public value is considered a production process similar to the one private sector organisations operate. Public agencies produce public value when they deliver collective goals (e.g., a cleaner environment or safer public transportation) that citizens define in the democratic process of political elections - what is defined by the authorising environment (Benington \& Mark Moore, 2010; Dahl \& Soss, 2014). On the other hand, the creation of public value implies a managerial action to balance multiple objectives of the creation of public value because they have to be traded off (Benington, 2007; Hartley, Alford, Knies, \& Douglas, 2017). For example, (CCTVs) can be deployed on buses and bus stops to increase public transportation safety. However, these deployments might curtail citizens' privacy. Public managers must deploy different policies being aware that public value can also be destroyed if public agencies or their partners perform activities that negatively impact different dimensions of the collective goals that citizens define during the democratic process of political elections (De Jong et al., 2017). Following this train of thoughts, the authors look at the creation of public value as the balancing of the combined values that are created by different outcomes, rather than as effective production of standalone outcomes that do not have to be traded off.

Therefore, balancing the values that are created by different outcomes is a fundamental prescription that public administration must follow to deliver public value and avoid generating citizens' disaffection (Williams, Kang, \& Johnson, 2016).

However, to be effective in the creation of public value, public administration must acknowledge that "the nature of public value is not fixed" (Moore, 1995, 55), because citizens' aspirations and needs, especially in the digital society, are highly mutable and variegated (De Bruijin \& Dicke, 2006; Zuboff \& Maxmin, 2002; Moore \& Khagram, 2004). In order to better respond to these mutable expectations, public administration should not only balance the values the different services they offer generate but also be more responsive and flexible to adapt and be able to provide the mutable expected services. Therefore, the creation of public value is not only concerned with satisfying a single collective need at a time (e.g., a more efficient public transportation system), and with multiple needs and expectations which might compete with or obliterate each other (Alford \& Hughes, 2008; Broussine, 
2003), but also with the ability to adapt to changes in value expectations.

Accordingly, to produce and deliver public value, it is not enough to satisfy a specific need, but is necessary to orchestrate the way in which the production configuration impacts on other needs and values over time, and to adapt when these needs change (Alford \& Hughes, 2008; Bryson, Crosby, \& Bloomberg, 2014; Cordella et al., 2018; Reynaers, 2014; Stoker, 2006).

The GaaP configuration facilitates the creation of public value since it increases the ability of public sector organisations to respond to variegated and mutable expectations and needs. The adoption of the platform configurations $\mathrm{c}$ an $\mathrm{p}$ otentially o pen the s ervice production process to external actors to better deliver services that meet citizens' expectations. For example, free access to anonymised open medical data enables third parties, such as universities, pharmaceutical companies, and start-ups, to produce many different types of treatment and digital applications which can help public agencies to provide better and more options of treatments to citizens (Kallinikos \& Tempini, 2014). However, the platform configuration might decrease the control public administration has over the value that these services deliver (Cordella \& Paletti, 2018). If healthcare data are not adequately anonymised, they can be misused by pharmaceutical or insurance companies to discriminate specific $\mathrm{c}$ itizens or $\mathrm{g}$ roups of $\mathrm{c}$ itizens. In order to create a right balance among the different $\mathrm{n}$ eeds a nd expectations, public administration must find the right way to anonymise data and limit the access only to those users who will guarantee not to create negative contributions (e.g., price discriminations) which have negative impacts on public value.

Therefore, from a public value perspective, the key challenge of the GaaP is to enable, control, and manage the dynamic combination of the needed resources, routines, and structures to adapt and respond to emerging and unpredictable citizens' needs, so that all the different values and expectations are simultaneously and dynamically fulfilled.

Building on a long tradition in information systems research that distinguishes between enabling information infrastructures and platform configuration, it is p ossible to a nalyse b etter the complex implications that the platform configuration has on the values that public agencies produce using it. The distinction between information infrastructures and platforms mainly concerns the level of control that the owner or controller of the technological architecture exercises (De Reuver, Sørensen, \& Basole, 2018).

The public sector has historically developed infrastructures, such as highway or railway systems, upon which third parties have developed innovative business propositions and services. Given the distributed nature of these infrastructures, the public sector has not been able to exercise a high level of control over the developments that build on infrastructure. In other words, the public sector cannot easily avoid negative impacts of these developments on society and on the values it aims to pursue. In recent years, public agencies have developed information infrastructures that provide support for the development of innovative services. In the light of Hanseth and Lyytinen's (2004) design theory, these information infrastructures, such as the Internet, are "shared, open (and unbounded), heterogeneous, and evolving socio-technical systems" (Hanseth \& Lyytinen, 2004, 4) whose design and evolution cannot be entirely controlled and managed. According to the authors, it is the interdependence among path-dependent developments that determines the trajectory of the evolution of these information infrastructures and the value it is able to generate. The lack of control over the development and evolution of these information infrastructures is very valuable to enable and foster innovation. However, this lack of control can negatively impact the values that public administration wants to deliver to society by fostering innovation through these technological architectures (Janssen \& Estevez, 2013). Thus, it is not surprising that public sector organisations are now increasingly investing in technological architectures that allow the enhancement of the level of control over the developments that occur upon or around these architectures. This is needed in order to avoid the negative effects that uncontrolled innovation can have on society and the values it pursues. According to Hanseth and Lyytinen (2010), and De Reuver et al. (2018), this transition towards a more controlled environment reflects the move from an infrastructure thinking to a platform thinking.

For example, public sector organisations provide open data sets, APIs, and digital identity systems that act as platforms upon which third parties can build new and innovative products or services. These platforms result in "evolving system(s) made of interdependent pieces that can each be innovated upon" (Gawer \& Cusumano, 2002, 2). These platforms provide standardised environments that facilitate the emergence of whole ecosystems of products and services whose growth is supported by the platform standardised environment (Brown et al., 2017). The platform configuration increases control of the development of these products and services, thus it allows public sector organisation to steer better and check the value these products and services deliver to society. This platform thinking has become increasingly relevant for the public sector (O'Reilly, 2011) to support the emergence of innovative services third parties provide and, hence, to better deliver services that fulfil social expectations and public value. Public administration must provide some core services and exercise centralised control through the development and the enforcement of policies and regulations. This allows the coordination of services which are provided by different actors, and the exploitaition of third parties' contributions for the production and delivery of public services in a way compatible with the value-generating proposition of the public sector (O'Reilly, 2011).

While the deployment and management of shared infrastructures have been at the centre of the action of public administration for a very long time, the adoption of the platform thinking raises new managerial challenges to effectively manage the value creation process these new platforms enable (Janssen and Janssen \& Estevez, 2013). This value is often associated with the positive impacts that the control and the standardisation of the development of services around the shared resources the platform architecture offers have on the efficiency of the production and the provision of public services. It is, in fact, not the case that platform projects in the public sector are core components of e-Government initiatives that are developed under the growing pressure of "doing more with less", with the aim of leaning government processes (Janssen and Janssen \& Estevez, 2013). GaaP projects are conceived as responses to the lack of value joined-up government (JuG) initiatives have delivered (Cordella \& Bonina, 2012; Margetts \& Dunleavy, 2013). These initiatives themselves have been responses to the failure of e-Government projects that the first wave of New Public Management (NPM) reforms drove. These reforms led to the proliferation of siloed technological development, which created barriers to the development of effective and efficient e-Government solutions (Cordella \& Iannacci, 2010).

As discussed above, the characteristics of the platform configuration support the GaaP initiatives to simultaneously increase the coordination within public administration and enable access to external resources and competencies for better production of public services.

Government organisations provide services in many different domains. In order to exploit the values that the platform configuration can add to service production and delivery and to best arrange service production and delivery in the different domains, government organisations will adopt different platform configurations.

\subsection{Gaap, orchestration and creation of public value}

The GaaP is not a monolithic configuration to support and enable a predefined configuration of service production and delivery. The GaaP is indeed a bundle of platforms deployed to coordinate and control service productions in the different domains of government intervention. As a result, the GaaP is a platform of platforms in which each 
platform enables a subset of government services. Ideally, the GaaP coordinates and controls service production and provision by providing a set of rules and standardised services that define how the platforms that are deployed to support the individual services will balance and coordinate each other. As a result, the GaaP exercises more control than a traditional information infrastructure, but less than a traditional platform, whose domain is clearly defined and demarcated (Hanseth \& Lyytinen, 2004). The GaaP provides a valuable framework to enable innovative and open production processes, which are needed to enhance the value that public services generate and deliver. At the same time, the GaaP preserves a level of centralised control to provide services that fulfil social expectations in aggregate and, thus, to deliver public value.

Therefore, GaaP deployments that aim at delivering public value should coordinate service productions that occur across the different platforms and choose the right techno-institutional configuration. The technological configurations of the different platforms en able service production. In order to create public value, service production must be coordinated, so that it does not generate negative cross effects (Cordella et al., 2018). The necessary coordination to balance these effects requires multidimensional, institutional, and technological elements the traditional coordination theory does not fully consider (Malone \& Crowston, 1994). The GaaP aiming at producing public value requires specific organisational capabilities to adapt to the dynamic changes that occur as a result of the multidimensional independences that shape the open and distributed production ICT platforms mediate (Aaltonen \& Lanzara, 2015). These organisational capabilities resolve in specific governance mechanisms that support the coordination of distributed social production aiming at the creation of specific values (Aaltonen \& Lanzara, 2015). Here, we refer to these governance mechanisms as orchestration. The notion of orchestration has already been used in literature to define $\mathrm{s}$ imilar g overnance $\mathrm{m}$ echanisms. $\mathrm{F}$ or example, Queiroz, Tallon, Sharma, and Coltman (2018) discuss orchestration as a key capability to enable organisations to properly configure their IT applications portfolio to adapt to market dynamics. While this definition of orchestration is relevant to discuss how the configuration of IT applications is governed, it is not enough to explain the governance mechanisms that are needed to configure the technological architecture and the organisational processes that shape and are shaped by GaaP configurations. Similarly, Janssen and Estevez (2013) refer to orchestration as a governance mechanism that coordinates the actions of the different $s$ takeholders $w$ ho a re i nvolved in the production of public services. Also, in this acceptation, orchestration does not involve the design and configuration of the technological platform that mediates the interaction among the different a ctors and organisations that are involved in the production of public services.

Since the GaaP involves both organisational and technological dimensions that define a c omplex techno-institutional a ssemblage, we define o rchestration a $s$ the $g$ overnance $m$ echanism $t$ hat $m$ oulds the GaaP technological and institutional configuration to d eliver public value. These governance mechanisms require negotiating the regulatory regimes that are embedded and structured in the technological architectures with those that are embedded and structured in the institutional arrangements that govern different public agencies (Cordella \& Contini, 2012). Hence, orchestration is a key governance mechanism that shall be put in place by public sector organisations that rely on the GaaP configuration to better create public value.

\subsection{Production of public services through the GaaP}

The GaaP is an organisational model that enables the dynamic combination of resources, routines, and structures to adapt and respond to organisations' emerging and unpredictable needs and challenges (Ciborra, 1996). Platform organisations develop around independent components (organisations, divisions, individual developers or citizens) that are integrated into flexible a nd d ynamic c onfigurations. These configurations are mediated by technological artefacts that provide unique and more efficient and effective organisational responses to the challenges of dealing with dynamic environments (Ciborra, 1996). In the context of public administration, the adoption of the platform organisational model can support different modes of production of public services (Cordella et al., 2018; Janssen \& Estevez, 2013).

ICTs are a fundamental enabler of the platforms that coordinate the collaboration between public and private actors, and enable public agencies to increase the efficiency of the production, combining internal resources or external resources (Baldwin \& Jason Woodard, 2008; Kallinikos, 2011). The need to enable the production and to combine different resources has changed the role of public administration, which is not anymore the sole producer of services, but an orchestrator and enabler of the co-production of the services. Public administration enables and orchestrates the contributions of public and private actors to produce more efficient public services (Janssen \& Estevez, 2013).

To date, the literature has shown that the adoption of the platform model can help to improve the efficiency of public services (Brown et al., 2017; O'Reilly, 2011; Linders, 2012; Janssen \& Estevez, 2013). However, the extent to which the platform configuration can help public administration to deliver efficient public services, but also meet other public values (e.g., fairness, equality, safety, privacy, or care for the environment), remains unclear.

The platform configuration, like every other configuration that supports and enables the production and delivery of public services, has a direct impact on the creation and delivery of public value (Cordella et al., 2018; Cordella \& Bonina, 2012; Moore, 1995).

\section{Theoretical framework}

The platform organisation is an evolving configuration which is made of interdependent components that develop and change over time (Ciborra, 1996; Cusumano \& Gawer, 2002). Public administration organised as a platform is a hybrid model of an organisation that is able to simultaneously embed different levels of control over the service production process through three different types of platform configurations (Brown et al., 2017).

"Internal platforms" are a set of common and shared structures which are intentionally built to evolve or to enable the production of different products or services within a given organisation. An example of internal platform can be a hospital electronic medical healthcare system which provides a common platform to exchange medical data within departments in the same hospital. This type of platform embeds a close control over the use of the data, and confines the value creation process to the resources and competencies that are internal to the organisation. It usually generates value for public services that need a high level of internal control.

"Supply chain platforms" replicate the same shared structure and benefits of internal platforms among different public agencies that need to exchange information and cooperate to produce public services. The platform GOV.UK.Pay is an example of a shared infrastructure that enables all public agencies to receive payments online, without creating their own payment system. This type of platform can embed a medium control over the value creation process, and is suitable to support the joined-up mode of production which is typical of core public services, such as payment or identification services, that are useful for all public agencies.

"Industry platforms" are a set of organisational structures and infrastructures that enable third parties (i.e., companies or citizens) to coproduce public services. An example is the open data platform of Transport for London (TfL). It has enabled more than 7000 developers to create applications (e.g., Google Maps or CityMapper) that complement the already existing information service TfL provides in tube stations, bus stops, or on the official TfL website. This platform embeds a low level of control of the value creation process, and is more suitable 
Table 1

Types of platform and mode of production.

\begin{tabular}{|c|c|c|c|}
\hline Type of platforms & Internal platform & Supply chain platform & Industry platform \\
\hline Control & High & Medium & Low \\
\hline $\begin{array}{c}\text { Type of Public } \\
\text { Service }\end{array}$ & $\begin{array}{l}\text { Suitable to produce services that } \\
\text { need a high level of control over the } \\
\text { final outcome like the policing } \\
\text { service. }\end{array}$ & $\begin{array}{l}\text { Suitable to produce services that need a high level of control } \\
\text { over the final outcome and that facilitate the cooperation } \\
\text { among public agencies like payments or identification of } \\
\text { citizens }\end{array}$ & $\begin{array}{l}\text { Suitable to produce services that do not need a high } \\
\text { level of control and that need many resources to be } \\
\text { effective such as the public transportation service }\end{array}$ \\
\hline
\end{tabular}

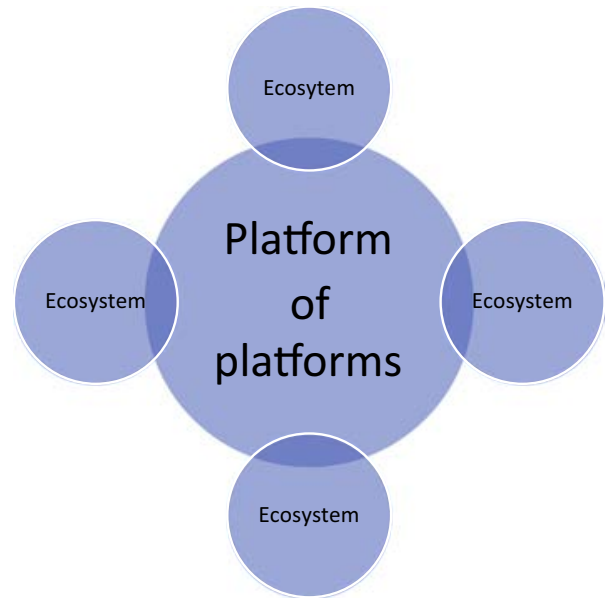

Fig. 2. The GaaP as a platform of platforms.

to support the production of services that need to and can be co-produced with external actors (Cordella \& Paletti, 2018) (Table 1).

All the national and local public agencies which compose the public administration need to produce different types of services simultaneously; some of these services need more control over the final outcome than others. Same services require strict administrative control to deliver the value they embed. To issue a passport which is internationally recognised requires to follow specific procedures and fulfil requirements that can only be granted by strict control over the procedures and the agents involved in the process. Other services do not require the same level of control to deliver the expected value. The provision of information about the schedule and status of public transportation does not require strict administrative and procedural control the guarantee the value they deliver. In this case the value is in the accuracy of the information provided rather than on the source of the provider of the information.

The nature of public services and the level of administrative control required to deliver the expected value define the most suitable characteristics the chosen platform configuration must provide. Since multiple services must be produced and different services require different characteristics in the supporting platform configuration, multiple platform configurations must be deployed, managed, and maintained to deliver all the needed public services. As a result, the core platform of a GaaP model is a platform of platforms where internal, supply chain, and industry platforms coexist and interplay.

The different platforms used by national and local public agencies to produce public services control and shape the service production and provision processes. The platform configuration determines the organisational and technological dimensions that define the organisational configuration and capacity used by the public administration to produce and deliver public services and hence constitutes the operational capability of public administration, which is indeed the "result of the confluence or intertwining of ICT and organisational features" (Zammuto, Griffith, Majchrzak, Dougherty, \& Faraj, 2007, 752).

In order to be able to create public value, the orchestration of the different configurations that define the organisational and technological features of a GaaP requires a holistic representation and understanding of the entire public administration that relies on the GaaP model (Brown et al., 2017; Eaton, Elaluf-Calderwood, Sørensen, \& Yoo, 2015). This means that the public administration must be conceived as an organisation ready to redefine its boundaries, in order to constantly adapt to external changes and needs. The representation of a public administration as a platform is inevitably linked to the existence of a participatory ecosystem that enables third parties to co-produce public services (Brown et al., 2017; O'Reilly, 2011). Public administration as a platform is based on a stable centralised core (i.e., the platforms) (Olleros, 2008; Baldwin \& Jason Woodard, 2008) that is integrated into its peripheral components, which are also defined as modules of the ecosystems. The centralised platform contains all the needed regulations, policies, services (e.g., payment, identification, and security), and infrastructures (material and immaterial) to favour generative ecosystems where public agencies, as well as external actors, can co-produce public services (Eaton et al., 2015; Henfridsson \& Bygstad, 2013; Olleros, 2008; Yoo, Henfridsson, \& Lyytinen, 2010). A public administration which is organised as a platform similar to complex platforms, such as Apple, Amazon or Google, enables multiple ecosystems that are different in their nature, but that effectively coexist and interact (Fig. 2) (Eaton et al., 2015; Baldwin \& Jason Woodard, 2008; Boudreau \& Lakhani, 2009).

The existence of different ecosystems is required, because a public administration's scope includes different domains, such as healthcare, transportation, education, and defence. Each ecosystem has different characteristics and, thus, requires different boundary resources, which are "the software tools and regulations that serve as the interface for the arms-length relationship between the platform owner and the application developer" (Ghazawneh \& Henfridsson, 2012, 174). The boundary resources evolve as a result of the activity of orchestration of the production, and are used to address and constrain the generativity of ecosystems (Eaton et al., 2015; Ghazawneh \& Henfridsson, 2010; Henfridsson \& Bygstad, 2013; Yoo et al., 2010) (Fig. 3).

The ecosystems can be closed or open. They are managed by the public agencies in charge of a specific domain and for the production of specific public services. An ecosystem is closed if it contains services and products which are produced by public agencies and by selected contractors or external actors. Conversely, in an open ecosystem (i.e. open data), no boundaries or barriers are imposed on all those who are interested in producing complementary services or products (Olleros, 2008).

All these organisational features are deeply intertwined with the architectural dimension, which represents the technical components of the platform (Baldwin \& Jason Woodard, 2008; Ghazawneh \& Henfridsson, 2012; Katz \& Shapiro, 1994; Ulrich, 1995). The architectural dimension of a public administration as a platform consists in extensible material and immaterial infrastructures that provide core functionalities to ecosystems of modules which embed different types of services (Baldwin \& Jason Woodard, 2008; Eisenmann, Parker, \& Van Alstyne, 2006; Tiwana, Konsynski, \& Bush, 2010). A module is an addon material or immaterial component that connects the platform to an added functionality or public service (Baldwin \& Jason Woodard, 2008; Sanchez \& Mahoney, 1996). Modules are collected in specific ecosystems which are internally and externally interoperable (Cusumano \& Gawer, 2002). Interoperability is guaranteed by interfaces which have 


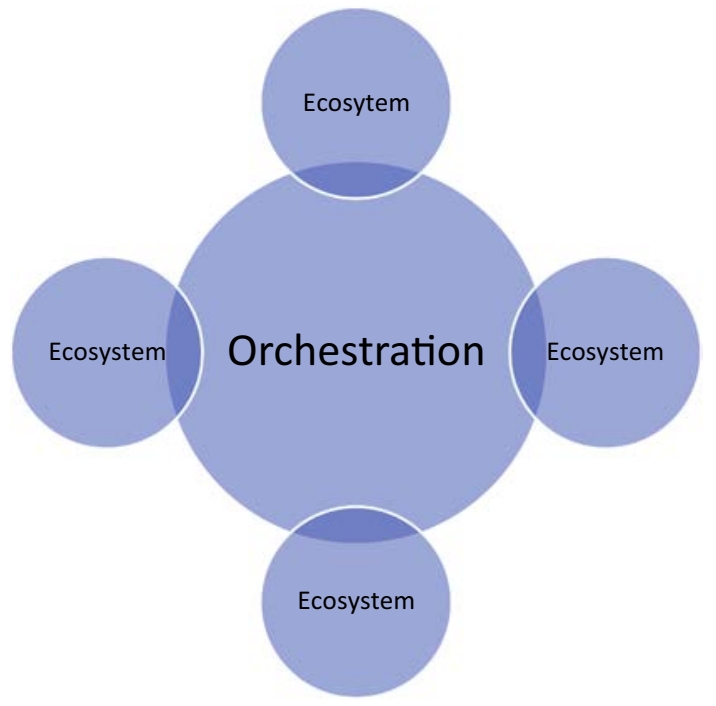

Fig. 3. GaaP orchestration.

technical specifications/standards and design rules that enable modules to exchange information with other modules or with the infrastructure (Katz \& Shapiro, 1994).

In order to be able to create public value, a public administration as a platform needs to have three technical properties that make the public administration architecture able to support different service production processes and to be adaptable (Baldwin \& Jason Woodard, 2008):

a. Decomposition. It should always be possible to decompose and break down hierarchically the platform into its atomic, constituent, and basic functionalities. The possibility to decompose a platform is necessary to minimise the overall complexity of the architecture and the interdependences among the different components.

b. Modularity. Each modular component must be independent from the rest of the subsystem, in order to avoid changes in the module affecting the behaviour or functionality of the platform or of other modules.

c. Design rules. Modules interact with the platform according to documented and predefined rules and standards. External developers must obey specific design rules to ensure interoperability between modules and the platform. Design rules must be stable, but versatile in the long run, not to constrain the variety and flexibility of the ecosystem.

From a public value perspective, the platform organisation provides fundamental resources to increase the organisational capability to create and deliver public value, enabling a new way to configure (orchestrate) service production and delivery (Fig. 4). The modularity of the platform organisation allows public administration to combine its elements into infinite configurations. The platform organisation can quickly adapt and respond to changes (Baldwin \& Jason Woodard, 2008; Ciborra, 1996) in citizens' needs and expectations by updating or redesigning modules to reconfigure services and respond to emergent and changing needs. As a result, a public administration as a platform does not carry the rigidity of the monolithic bureaucratic structure and can quickly adapt and be reconfigured, such as a construction made of LEGO bricks that, like in a bricolage (Strauss, 1962; Weick, 1993), can be constructed in infinite ways at any time (Brown et al., 2017; O'Reilly, 2011).

Moreover, the modules that organise the ecosystems allow the different agencies of public administration to orchestrate different public services and the contributions of public and private actors to these services, in order to deliver and preserve an array of public values. The modular nature of the platform organisation also supports an easy redefinition of the boundary resources (Eaton et al., 2015; Ghazawneh \& Henfridsson, 2010) which regulate what public and private organisations can do within the ecosystem, and, hence, the required level of control to preserve the creation of public value and delivery.

\section{Research setting and methodology}

This research used an explanatory case study methodology (Yin, 1994), sourcing data through interviews and documents. It used a hybrid approach of thematic analysis (Fereday \& Muir-Cochrane, 2006) that mixes deductive and inductive approaches. The implications of the research findings are relevant to explain how the characteristics of the platform organisational model help public administration to deliver public value.

Before undertaking the data collection, the authors identified the research question, the theoretical framework, and the research propositions which guided the data collection and analysis (Hudson \& Ozanne, 1988).

The authors chose the case of the GaaP development in Italy because of its relevance - the project is one of the most advanced in the design of a GaaP architecture - and because of the high level and open access that the researchers were granted.

The case study allowed the authors to analyse the GaaP organisation in its natural settings and helped them to get a deep understanding of the political, social, and technical factors that had favoured the adoption of the platform model (Benbasat, Goldstein, \& Mead, 1987). Therefore, the unit of analysis of the case study is holistic and is represented by the GaaP configuration introduced by the the Italian reform (Yin, 1994).

The AgID, the Italian agency for digitalisation, and the Digital Transformation team, the public agency in charge of planning the digital strategy for the Italian public administration, were the two primary data sources for the case.

The table below outlines the different phases of the case study and summarises the data collection process, the sources of the data, and the characteristics of the collected data.

\subsection{Data collection}

The AgID and the Digital Transformation team are the two main sources of data. Data were collected in two phases, from April to December 2017. The first phase consisted in the documents collection and the third in the interviews with key actors in the development and implementation of the new digital strategy for the Italian public administration. In the first phase, the authors collected 56 official documents from the two agencies and 40 from newspapers, which contributed to build a strong understanding of the case. Two key documents revealed to be the Strategy for the Digital Growth and the Three-Year Plan for ICTs in Public Administration 2017-2019. These documents explain in detail how the Italian public administration's GaaP initiative works, and offer a very detailed outline of the transformation plan. The researchers collected other official documents from the Medium blog of the AgID and the Digital Transformation team. Several newspaper articles integrated the understanding of the changes the GaaP reform had brought about. After the document analysis, phase two, the authors conducted 10 semistructured interviews. The interviews lasted between 30 and $70 \mathrm{~min}$. Interviewees included members of Parliament and high-level managers who were directly involved in the planning of the digital reform and who were in charge of the development of the platforms and other components of the GaaP project. The authors used multiple sources of evidence (Table 2) to validate the findings(Carter, Bryant-Lukosius, DiCenso, Blythe, \& Neville, 2014; Yin, 1994), and to have a stronger understanding of how the production of public services would change once all the digital platforms would be developed and the ecosystem would start to be populated by public and private data. Also, during the interviews, the researchers discussed two hypothetical examples related to mobility 


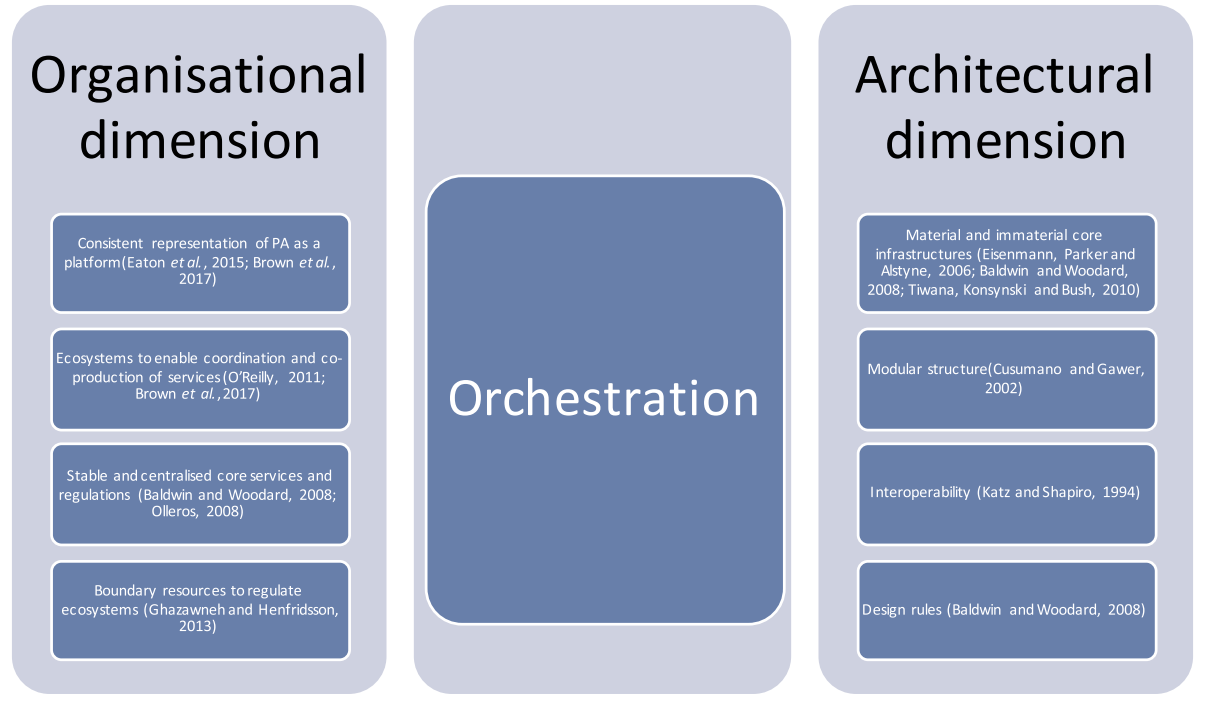

Fig. 4. Organisation and technical characteristics of the GaaP.

and healthcare services, in order to ensure the understanding of how this model of organisation would change the production of public services and public value delivery.

\subsection{Data analysis}

The authors analysed all the documents with the use of NVivo qualitative software, through a hybrid approach of thematic analysis (Fereday \& Muir-Cochrane, 2006) that mixes deductive and inductive approaches. The hybrid approach not only identifies, analyses and reports patterns within data(Braun \& Clarke, 2006, 6) on a deductive a priori approach (Crabtree \& Miller, 1999) but incorporates also the data-driven inductive approach (Boyatzis, 1998). The mix of inductive and deductive approach also distinguishes the hybrid analysis from the grounded theory which is usually based only on pure induction (Glaser \& Strauss, 1965). Overcoming the limitations of pure thematic analysis and of grounded theory the hybrid approach of thematic analysis is particularly suitable to serve the explanatory nature of this study. The themes identified in the theoretical framework were usefull to address the data analysis. However the researchers were aware that the theoretical framework deeply grounds on private sector literature which is limited to analyse the GaaP. To overcome this limitation the authors have decided also to adopt an inductive coding to let themes emerge directly from the data and keep the auhtors understanding open to novelties that the egovernment theory about GaaP has still not considered.

Before starting the in-depth analysis of the case, the researchers created a codebook based on the themes identified in the theoretical framework. During the process of analysis, the codebook was enriched

Table 2

Data collection methods.

\begin{tabular}{|c|c|}
\hline I Phase & Description \\
\hline \multicolumn{2}{|l|}{ Data collection based on secondary sources } \\
\hline Strategy for the digital growth 120 pages $^{1}$ & $\begin{array}{l}\text { The preliminary document which addresses the vision and the reforms necessary to adopt the platform } \\
\text { model in the Italian Public Administration }\end{array}$ \\
\hline $\begin{array}{l}\text { The Three-Year Plan for information technology in the Public } \\
\text { Administration } 133 \text { pages }^{2}\end{array}$ & $\begin{array}{l}\text { A detailed plan for the development and the launch of the digital infrastructures and core services necessary } \\
\text { to support the platform model of public administration }\end{array}$ \\
\hline 27 Medium articles Digital Transformation Team ${ }^{3}$ & $\begin{array}{l}\text { Articles written by the managers from the Digital Transformation Team to update and explain their progress } \\
\text { and initiatives }\end{array}$ \\
\hline 28 Medium articles Italian Digital Agency(AgiD) ${ }^{4}$ & $\begin{array}{l}\text { Articles written by the managers from AgiD to explain the activities and the projects related to the new } \\
\text { digital strategy }\end{array}$ \\
\hline 40 newspaper articles & Articles from major Italian News Papers that reported interviews and explanations of the new reform \\
\hline II Phase & All the documents were analysed through a hybrid approach of thematic analysis using NVivo software \\
\hline \multicolumn{2}{|l|}{ Document analysis } \\
\hline \multicolumn{2}{|l|}{ III Phase } \\
\hline \multicolumn{2}{|l|}{$\begin{array}{l}\text { Data collection based on primary sources } \\
10 \text { interviews }\end{array}$} \\
\hline 3 Members of Parliament & $\begin{array}{l}\text { The three congressmen from different political parties coordinated and developed the digital reforms of the } \\
\text { Italian Public Administration }\end{array}$ \\
\hline 2 High-level public managers & $\begin{array}{l}\text { The two public managers from AgID were in charge of the strategic planning and coordination of national } \\
\text { and local actors }\end{array}$ \\
\hline 3 High-level public managers of Digital Transformation Team & $\begin{array}{l}\text { The three public managers of the Digital Transformation team were directly involved in the development of } \\
\text { the platforms necessary to provide the core services }\end{array}$ \\
\hline 1 High Manager from the Data Protection Authority & $\begin{array}{l}\text { The manager was in charge of the data protection and contributed to the development of the strategy. The } \\
\text { manager studied how the platform configuration can be used to govern the data privacy }\end{array}$ \\
\hline 1 High Manager of Italian Regulatory Authority & $\begin{array}{l}\text { The manager was in charge of market regulatory policies and contributed actively to the development of the } \\
\text { strategy. }\end{array}$ \\
\hline
\end{tabular}

\footnotetext{
1 https://www.agid.gov.it/sites/default/files/repository_files/documentazione/strat_crescita_digit_3marzo_0.pdf.

2 https://pianotriennaleict.italia.it/assets/pdf/Piano_Triennale_per_1_informatica_nella_Pubblica_Amministrazione.pdf.

3 https://medium.com/team-per-la-trasformazione-digitale.

4 https://medium.com/@AgidGov.
} 
with other themes emerging from the data analysis (Haas \& Kraft, 1984; Trochim, 1989). Examples of categories derived from the theoretical framework are the consistent representation of public administration as a platform, the presence of material and immaterial core infrastructures, the provision of core services, the existence of ecosystems, while open source elements emerged from the data analysis.

The codebook was implemented on NVivo and it guided the analysis of the documents. However, the analysis was not sequential as in the classic thematic analysis(Braun \& Clarke, 2006). The combination of deductive and inductive approaches resulted in an iterative process because themes were added and continuously reviewed according to the input coming from the data (Fereday \& Muir-Cochrane, 2006). The document analysis provided a deep understanding of the case, and it allowed the researchers to lead more informed interviews. In fact, building on the outcome of the document analysis, during the interviews, the authors were able to discuss scenarios of how the platform development impacts on public services. The discussions mainly focused on the changes in the domains of public transportation and healthcare, and on how the platform model would impact on the creation and delivery of public value.

\section{The case of the Italian public administration as a platform}

The reforms the Italian government has undertaken to develop the needed platform components to enable the transformation of the administration into a GaaP organisation started in 2015. Under a growing political pressure for the development of a national e-Government strategy, the AgID launched a plan for the development of national platforms to provide core digital services (e.g., identification payments to all public agencies at all levels of government procurement and artificial intelligence) and enhancement of competencies and skills. Following the successful path the UK Government Digital Services (GDS) had outlined, the AgID's platforms are planned to avoid duplications of investments for similar services at the local level. Moreover, the platforms aim at supporting the development of ecosystems where public and private actors can produce new services. These new services are designed as a modular structure, which enables the evolution of public services and reduces the complexity of the coordination among the agents that are involved in the processes of service production and delivery. Key components of the shared services are catalogues of private and public open data, which favourite the collaboration among public agencies and the co-production of public services with external actors, such as companies or NGOs.

The plan for the adoption of the platform organisational model is the response to the fragmentation and "silos structure" of the organisational structure of the Italian public administration, and to the inefficiency it has generated at the national and local levels. For decades, every public agency in Italy has been directly responsible for the development of its own digital services, in order to improve internal efficiency. The lack of coordination in these developments created inequalities in the service delivery across the 20 Italian regions. Regions such as Tuscany, Lombardy, Emilia Romagna, and Trentino made conspicuous investments in e-Government, but failed to coordinate. This resulted in duplications of digital infrastructures and created interoperability problems at the national level. In order to overcome these coordination problems and inequalities among regions, the government embarked on the development of solutions for the provision of integrated services and for the reform project that led to the GaaP initiative. The need for more integration among digital services offered by different public agencies led to the investments in three national crossagency platforms: pagoPA, SPID, and Anagrafe Nazionale Popolazione Residente (ANPR), the national register for residents in Italy. pagoPa is a service payment platform that was imposed by law in $2012 .^{1}$ The platform standardises and unifies all the digital payments across the

\footnotetext{
${ }^{1}$ pagoPA was required by article 5 of the CAD (Codice dell'Amministrazione Digitale) and by the law D.L. 179/2012.
}

entire Italian public administration, and eliminates all the digital payment solutions individual national and local agencies had developed. SPID provides a national and cross-departmental identification solution. SPID was imposed by law in $2014,{ }^{2}$ in order to provide a single way to identify citizens for digital services and avoid duplication, inefficiencies, and redundancies a multitude of independent and incompatible identification systems had generated. The development of ANPR was imposed by the law in 2012. ${ }^{3}$ ANPR unifies all the registries single municipalities across the country had developed and autonomously managed. These three platforms also became the backbone of the future GaaP architecture. However, although the development of these platforms and other similar initiatives improved the coordination at the national level, it did not allow to overcome all the coordination and interoperability challenges.

In March 2015, the AgID started a radical reform of the digital strategy of the Italian public administration to tackle these problems. It developed a GaaP model to decrease the inefficiencies, and offer personalised public services to better meet citizens' needs and expectations.

As one of the interviewees revealed, the planning was inspired by the E015 platform ${ }^{4}$ that was developed to support the 2015 Expo in Milan:

"We were inspired by the experience of the E015 platform that was developed for the Milan Expo and that builds on the API model.... E015 uses private and public APIs to provide public transportation services....you can have the data about flight status, that is private, and the data about underground transportation, that is public....There is also a common catalogue of the events of private and public agencies made available by the platform." 5

Inspired by this approach, the AgID planned to offer integrated services through a dashboard similar to the one available on Android or iOS-powered smartphones. The dashboard will provide access to an ecosystem of public and private services, such as public healthcare, education, tax payments, banking or services to monitor electricity or water consumption. ${ }^{6}$

The GaaP model of the Italian public administration is described as an "operating system" that is evolvable and adaptable. It relies on physical infrastructures, such as data centres, cloud, and telecommunication infrastructures, and on intangible infrastructures. The intangible infrastructures are constituted by all the data of public organisations and by seven platforms. The following six are already available, even if they are not yet fully adopted: CIE (electronic identity card); SPID (digital identity); pagoPA (payments); NoiPA (human resources management); FatturaPA (electronic invoice); ANPR (national register of residents). Finally, the seventh platform, ComproPA (eProcurement), is not fully developed, yet (Fig. 5).

An interoperability framework governs the data exchange and interoperability across the seven platforms and among the datacentres the different public agencies maintain. The interoperability framework consists of specific design rules and resources, such as documents and software developer toolkits (SDK). The interoperability framework facilitates and coordinates public and private organisations' access to data. The core of the interoperability framework is the data analytics framework (DAF), which collects and processes data from public agencies and external actors to make data publicly available and accessible through a user interface. The data uploaded are monitored by the data protection authority, that protects the citizens' privacy and

\footnotetext{
${ }^{2}$ https://www.agid.gov.it/sites/default/files/repository_files/leggi_decreti_ direttive/dpcm_24_ottobre_2014a.pdf

${ }^{3}$ http://www.normattiva.it/uri-res/N2Ls?urn:nir:stato:decreto.del. presidente.del.consiglio.dei.ministri:2013-08-23; 109

${ }^{4}$ http://www.e015.regione.lombardia.it/

${ }^{5}$ From an interview to a manager of the AgID.

${ }^{6}$ https://medium.com/team-per-la-trasformazione-digitale/datiinteroperabili-open-pubblica-amministrazione-data-analytics-framework4eb53dafd618
} 


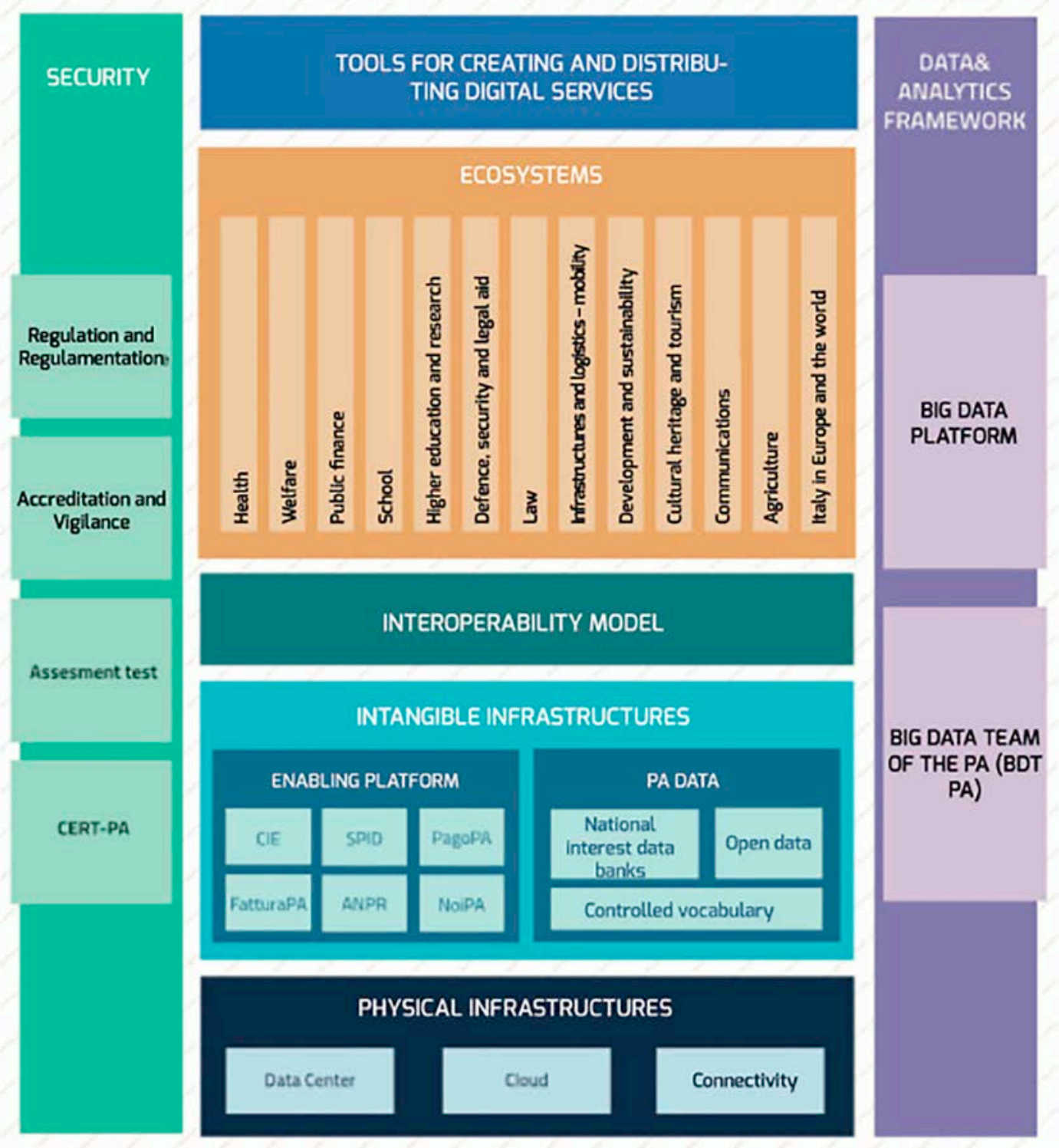

CHANGE MANAGEMENT

Fig. 5. Structure of the Italian operating systemi (http://pianotriennale-ict.readthedocs.io/en/latest/doc/02_modello-strategico-di-evoluzione-dell-ict-della-pa. html).

assesses how the other public agencies use their data. As one of the interviewees clarified, the different ecosystems and APIs "are designed and governed according to the Italian constitutional principle of vertical (different levels of government/public agencies corresponds different duties) and horizontal subsidiarity (collaboration with civil society)". ${ }^{7}$

Therefore, each level of the government and the different public agencies are responsible for regulating data access according to their administrative and political responsibilities. The data are accessible through an open data platform that contains public APIs ${ }^{8}$ which are available on the Developers Italia $^{9}$ community website. The AgID and the Digital Transformation team launched Developers Italia to better engage the developers' community.

Developers Italia is dedicated to developers of digital public services.

\footnotetext{
${ }^{7}$ From an interview to a Member of Parliament.

${ }^{8}$ https://developers.italia.it/it/api

${ }^{9}$ https://developers.italia.it/en
}

It provides a list of all the available public and private APIs, source code, a modern document management system, and interactive tools that facilitate developers from public agencies and companies to create new digital services. In order to support the utilisation of Developers Italia, on the 7th and 8th of October 2017, the Digital Transformation team organised Hack.Developers, ${ }^{10}$ a hackathon that involved 800 developers, who were organised into 116 teams, with 200 mentors, who worked to improve the enabling platforms (e.g., PagoPA or SPID), develop public services on these platforms, or use the available APIs.

\section{Analysis of the case}

The reform the AgID and Digital Transformation team has led embeds the plan to transform the Italian public administration into a GaaP configuration. As the literature highlights, this configuration resembles

\footnotetext{
${ }^{10}$ https://hack.developers.italia.it/cose/
} 
the one of an "operating system" (Brown et al., 2017; E aton et al., 2015). The "operating system of the country" is "a series of fundamental blocks upon which services for citizens, the public administration, and enterprises are built with modern digital products". ${ }^{11}$ The operating systemis a modular structure that helps to minimise interdependencies and the overall complexity of the public administration architecture, which can be easily decomposed and recomposed, according to infinite configurations guaranteeing organisational and architectural adaptability (Baldwin \& Jason Woodard, 2008; Janssen \& Estevez, 2013). The modular infrastructure helps the public administration to be more flexible ( Ciborra, 1 996; B aldwin \& J ason W oodard, 2 008; O'Reilly, 2011; Brown et al., 2017) and adapt the production of public services to better meet citizens' needs and expectations that continuously change. In the case of the Italian reform, the modular structure of the organisational configuration is s ustained by different ty pes of pl atforms (a platform of platforms), which offer core services for all public agencies and also enable the co-production of different services (Cusumano \& Gawer, 2002).

The Italian approach to the development of a GaaP model well integrates and orchestrates the seven platforms to support the propositions of value creation of individual services and the public administration's overall logic of public value creation.

The seven different platforms that are at the core of the reform simultaneously embed different levels of control o ver the service production process (Brown et al., 2017), while exploiting the value the ecosystems with which they intertwine provide (Table 3 ).

NoiPA $^{12}$ is designed as an internal platform. NoiPA increases the internal efficiency of public agencies by standardising human resources procedures, such as the management of contracts and salaries, but also of dedicated services and discounts private companies offer to public employees. The platform leverages on two different e cosystems. One consists of the public agencies' human resources departments, and the other ecosystems are represented by the companies that offer dedicated services to public employees, such as insurances and banks. The platform currently serves 2 million employees, and its adoption is growing.

The pagoPA ${ }^{13}$ platform can be classified as internal, supply chain, and industrial platforms. pagoPA provides payment services for public administration and also for private organisations that co-produce public services. pagoPA has two ecosystems: the first ecosystem contains the payment service providers (PSPs), such as banks and financial companies as Paypal or Mastercard (currently 400 active PSPs); the second ecosystem consists of the organisations that use the platforms $(17,000$ public agencies, that is $73 \%$ of the public agencies in the Italian public administration, currently use pagoPA). It is an internal platform because it helps each public agency to facilitate the payment for its services through a standardised infrastructure, which already has different payment provider options. It is a supply chain platform because it simplifies c ross-payments a mong $\mathrm{p}$ ublic a gencies $\mathrm{f}$ or $\mathrm{s}$ hared public services, and it can also be considered as an industry platform, because private companies that co-produce public services can use it.

SPID $^{14}$ can also be classified as an internal, supply chain, and industrial platform. It also has two ecosystems: the ecosystem of identity providers, in charge of providing the digital identity to citizens; and the ecosystem of public and private organisations that use this platform to identify the user of their digital services. SPID provides a standardised infrastructure to identify users, and can be used as an internal platform to allow public employees to access and classify digital documents, or to perform other operations that are pertinent to the needs of the unit or organisation to which they belong. SPID can also be used as a supply

\footnotetext{
${ }^{11}$ https://medium.com/team-per-la-trasformazione-digitale/from-seattle-toroma-innovation-citizens-talents-6b8c6c06002b

12 https://noipa.mef.gov.it/

13 https://www.agid.gov.it/it/piattaforme/pagopa

${ }^{14}$ https://www.spid.gov.it/
}

chain platform since it provides a unified identification solution to access public services different administrations offer. SPID is also an industry platform because it can be used by both public agencies and companies as an identification system for their digital services. SPID is also used by citizens to sign contracts digitally. Currently, 2,785,393 SPID accounts have been released.

The electronic identity card (CIE), ${ }^{15}$ thanks to its integrated microchip based on radio frequencies, memorises biometric and personal data of Italian citizens and represents a pure example of industry platforms. It can potentially support an ecosystem (which is still underdevelopment) of services private and public organisations offer. For example, once the process of digital transformation will be completed, the police will be able to scan the CIE and access car licences and other information. The CIE can also be used to store train or bus tickets or as a badge to access an office, a gym or a stadium. Currently, 5,123,766 CIE have been realised.

The $\mathrm{ANPR}^{16}$ is a supply chain platform that unifies all the residence registries of the 7978 Italian municipalities. Thanks to the ANPR, public agencies can access a single platform to get easilystandardised data. This provides the enabling architecture for the development of integrated cross-agency services. For example, ANPR is a fundamental digital service that enables the exchange of National Medical Health Records across different hospital organisations. Currently, 604 municipalities have joined the ANPR and more are expected to join.

FatturaPA ${ }^{17}$ is an internal platform that increases the efficiency of public agencies by providing a standardised system to manage electronic invoices. It is based on an ecosystem of public and private organisations that exchange electronic invoices when they buy and sell public and private services. The platform helps to increase public agencies' internal efficiency, because it collects, orders, and distributes all the electronic invoices according to a standard procedure that simplifies control from police or judicial agencies.

ComproPA is the national procurement platform which is still under development. However, it can be considered as an internal platform that provides a standardised and centralised system of procurement which is constantly updated according to the latest regulations and which facilitates a high level of control over all the national and local procurements.

All these platforms run on top of the interoperability framework defined by the DAF, the protocols, and regulations that facilitate the integration and orchestration of the services the different platforms and their associated ecosystems provide (Baldwin \& Jason Woodard, 2008; Henfridsson \& Bygstad, 2013; Olleros, 2008; Yoo et al., 2010). A public agency as well as a company can make data available to the public through the DAF, and can specify those who can access the data and the ecosystem on which those data should rely.

The orchestration of public value occurs ex-ante. A public agency assesses the impact according to its public interests and also to the impact on privacy.

"When public agencies upload their data on the DAF, they fill in a privacy form to ensure that the data comply with the privacy regulation and that the data will not impact on other services, so that negative effects on citizens' privacy will emerge." 18

\section{Accordingly:}

"Public agencies can decide the data that are made open and who can access the data....the data can be open to the public, partially open to some public agencies or only available within one agency. Since expectations and needs change, the data settings can be

\footnotetext{
${ }^{15}$ https://agendacie.interno.gov.it/

16 https://www.anpr.interno.it/portale/

17 http://www.fatturapa.gov.it/export/fatturazione/it/index.htm

${ }^{18}$ From an interview to a manager of the Digital Transformation team.
} 
Table 3

Different types of platforms.

\begin{tabular}{ll}
\hline Platforms of the Italian public administration & Types of platform \\
\hline $\begin{array}{l}\text { FatturaPA, pagoPA, ComproPa, NoiPA } \\
\text { pagoPA, NoiPA, ANPR, SPID } \\
\text { pagoPA, CIE,SPID }\end{array}$ & $\begin{array}{l}\text { Internal platforms- increase the internal efficiency } \\
\text { Supply chain platforms-increase coordination } \\
\text { Industry platforms- enable co-production of services }\end{array}$ \\
\hline
\end{tabular}

changed to adapt to the emergent needs and requirements."19

The DAF allows each public agency to orchestrate the creation of public value ex-ante, deciding the actors that can access the data and the conditions under which the data can be accessed. However, it also allows to adapt it ex-post to meet emerging needs.

The data which are available in each ecosystem can be accessed through an APIs catalogue on Developers Italia. This catalogue facilitates developers from public agencies and companies to access data from different ecosystems and platforms, and develop services that well suit citizens' need and expectations.

"For example, for those who want to offer it, it will be possible to develop, within one's own app, a geolocation service dedicated to locating crimes carried out over the last six months by calling on the specific API and exhibiting the requested (and continuously updated) data. It will also be possible to send, through the digital citizenship app, notifications to citizens on issues which are suggested by the recommendation engine (i.e., public debates on topics of interests and laws that affect one's own profession or geographical area)." ${ }^{20}$

Overall, the interdependences that are created among the platforms and ecosystems and managed by the interoperability framework increase the ability of public administration to respond to citizens' needs and expectations, and enhance the public value that is created. A GaaP model, in fact, exploits the generativity of the different ecosystems that originates from the interoperability among the ecosystems (Brown et al., 2017). The implicit decomposition and modularity of the GaaP service production model offer more options to citizens to personalise the consumption of public services and to satisfy their specific needs and expectations.

This is the reason why the AgID and the Digital Transformation team have focused on the generativity of the ecosystems and have created Developers Italia, ${ }^{21}$ on organising hackathons to stimulate public and private actors to develop more and better public services. However, the availability of more and better services is not enough to create public value. In fact, public agencies have to continuously orchestrate the creation of public value.

As one interviewee stated,

“...when a public agency notices that its data are used or misused by developers in a way that negatively affects citizens' or public agencies' privacy or security ... the agency must close the dataset or limit its access only to certain actors." 22

However, the generativity of the Italian GaaP model is also governed by the boundaries of the ecosystems which represent different policy-making domains, and by all the public and private actors who are involved in the production of services in that area (Eaton et al., 2015; Janssen \& Estevez, 2013).

"Each ecosystem identifies a thematic sector with characteristics of homogeneity. It includes public bodies and may also include private

\footnotetext{
${ }^{19}$ From an interview to a manager of the Digital Transformation team.

${ }^{20}$ https://medium.com/team-per-la-trasformazione-digitale/publicadministration-open-government-data-analytics-framework-27b7180cfb25

${ }^{21}$ https://developers.italia.it/

${ }^{22}$ From an interview to a manager of the Digital Transformation team.
}

individuals, such as associations, that, for various reasons, carry out important functions within the ecosystem. For example, the public finance ecosystem includes public entities, such as the Ministry of the Economy and Finance, the Ministry of the Interior, the Revenue Agency, the Regions, the Guardia di Finanza (Fiscal Police), as well as private entities as accountant, CAF (fiscal assistance centres), and fiscal practitioners ${ }^{23}$ ".

The creation of different ecosystems allows public agencies that belong to a different level of government to orchestrate the production of public services, according to their competences and needs (Brown et al., 2017; Page, Stone, Bryson, \& Crosby, 2015; Raymond, 2005; Janssen \& Estevez, 2013).

"Each public agency governs the data according to its competences and to pursue its policy goals. However, the data can become very useful to other agencies to better deliver their services". ${ }^{24}$

In the case of the public finance ecosystem, the Ministry of the Economy will govern all the data related to its competences in the field of national economic policy, the Revenue Agency will manage and govern data related to taxes, while the Fiscal Police (Guardia di Finanza) will manage the data related to its investigation and criminal records.

"Public agencies exchange and access data within their own ecosystems and across different ecosystems to produce their services". ${ }^{25}$

Therefore, to produce public services, public agencies need to access data that belong to other public agencies in their ecosystems, but also from public agencies that belong to other policy domains and their ecosystems.

It is essential to highlight that, according to interoperability policies and regulations, the public agency that owns the data must decide the data that are open and those that have restricted access. Therefore, through data management, public agencies can influence public service production across different ecosystems:

"A public agency can knock the door of another public agency and ask to close or limit the access to their dataset if they think they or third parties might use that data to threat public interests that are under their competence." ${ }^{26}$

Public value orchestration occurs not only within an ecosystem, but also across ecosystems, and it requires the collaboration among different public agencies to be effective.

“...Formal and informal institutional channels must be used to favour the dialogue among all public agencies and avoid that the digital initiative of one agency damages the policy domain of others....". ${ }^{27}$

\footnotetext{
${ }^{23}$ http://pianotriennale-ict.readthedocs.io/en/latest/doc/06_ecosistemi.html

${ }^{24}$ From an interview to a Member of Parliament.

${ }^{25}$ From an interview to a manager of the Digital Transformation team.

${ }^{26}$ From an interview to a manager of the AgID.

${ }^{27}$ From an interview to a Member of Parliament.
} 


\section{Lesson learnt and policy implications}

The analysis of the case study of the Italian public administration highlights the importance of orchestration in the recent reforms that aim at creating public value exploiting the platform configuration. The modularity of the platform configuration helps the Italian public administration to adapt and evolve the production of public services exploiting new services or technologies to meet citizens' needs better. However, public value is only created if the platform configuration is properly orchestrated.

"The services the platform and the datasets offer are assembled and disassembled in modules to create public services that meet different public interests. However, these services and datasets have to be always adapted to respond to changes in the service provision needs. The platform offers all the required functionalities to make the necessary changes." 28

Moreover, the creation of different ecosystems allows public agencies to orchestrate the contributions of public and private actors according to their competences and the public administration needs.

The case reveals that orchestration and the deployment of different ecosystems are two characteristics which make GaaP configurations able to deliver public value better.

To fully exploit the findings of the case, the authors discussed with the relevant stakeholders two examples of public services enabled by the Italian GaaP reform. The discussion helped to understand better how the GaaP configuration will transform e-Government services and address some of the possible policy implications of the GaaP configurations.

The first example relates to the digital mobility services that can evolve thanks to the services different platforms offer. The availability of real-time mobility data of all the transportation companies the OpenTrasporti ${ }^{29}$ platform makes available will enable applications such as GoogleMaps, Moovit, and CityMapper to offer multiple options for multimodal transportation planning which combine different transportation services (e.g., buses, car sharing, tube, bikesharing, and taxis) to help citizens reach their destination. The adoption of pagoPA by mobility companies enables citizens to choose through the app the payment options for the chosen transportation service that better suit their needs. The app will let citizens' access transportation services through a QR code or a reference number. The availability of multiple options of transportation and payment will help public administration to meet citizens' needs and then deliver more public value.

Each mobility service that participates with its APIs to OpenTrasporti is a module, and each payment option which pagoPA provides is a module, too. Therefore, if new mobility services or payments are created, they can be immediately available to the developers through these two platforms. In addition, the modularity allows the reconfiguration of the service production to accommodate emerging public needs. For example, it has been brought to discussion the opportunity to add the CIE (electronic identity card) to the mobility service configuration, in order to meet new anti-terrorism requirements to which a legislative decree draft of the Minister of Internal affairs refers. The Minister wanted to collect real-time data about the identity of the users of mobility services, specifically of those who rent a car through a car-sharing app such as Car2Go. In order to make this possible, a new configuration of the mobility service is needed. In this new production configuration, users will first scan their CIE on the mobility app, by taking a picture or using the NFC (Near-Field Communication) reader of the mobile phone; then, they will plan their route, pay the trip, and access the mobility service by scanning or showing their CIE. The data collected from the CIE will be forwarded to a database of the Ministry of
Internal Affairs. These data will allow tracing in real-time the identity of all the users of mobility service, ideally, to prevent terrorist attacks better. This specific orchestration of the service provision exploits different ecosystems to improve public transportation services and at the same time to protect society better from terroristic attacks, hence increasing the public value created. Public value can also be orchestrated within the ecosystem by each public agency, according to its competences.

"If in Rome a blizzard is predicted, the Roman Authority for Transportation can block the APIs of the scooter sharing and bike sharing services. The services will be temporarily unavailable on apps such as GoogleMaps or CityMapper to protect the citizens' safety, which is an essential service to be delivered in combination with transportation services." 30

In the latter case, the choice of not making available specific services is also a valuable orchestration among services and values, aiming at producing and delivering public value. However, the examples also reveal that the orchestration of public value needs to take into consideration the possible impacts of the new production configuration on other values.

The policy choice to connect the mobility service to the CIE to trace in real-time the identity of all the users of mobility service, to better prevent terrorist attacks has significant implications on the access to the mobility services. According to the current regulation, only Italian citizens that are resident in Italy can get the CIE; hence, Italians who are residents abroad, immigrants, foreigners, and tourists will not be able to use the mobility service because of the choice to connect the access to the mobility service to the CIE. Moreover, due to technical delays, not all of those who are entitled to have a CIE are able to have one, constraining even more the access to mobility services. The example reveals that in order to fulfil one specific value, in this case the Minister of Internal Affairs willingness to trace in real-time the identity of all the users of mobility service, it is possible to impinge upon the fulfilment of other values, such as the wide access to public mobility services. The policy choice to use the CIE to register on the mobility service might discriminate part of the population, preventing their access to the public transportation service. Given the interdependent nature of the platform of platforms at the core of the GaaP configuration each policy choice in one specific service domain can impact upon the value that is delivered by policies in other policy domains.

In our case, to limit this negative impact, a different production configuration with alternative forms of identification and access could be orchestrated. As one of the interviewees stated,

"if we decide to make CIE the only medium to access certain mobility services, those who do not have the CIE will be excluded from that mobility services. We have to think about other alternatives, otherwise many people will be discriminated and excluded from accessing these services. We need to explore a new configuration of the system functionalities to accommodate the different stakeholders' needs and expectations." ${ }^{31}$

However, this alternative choice while widening the access to public services would have impinged upon to ability of the Ministry of Internal Affairs to trace in real-time the identity of all the users of mobility service, to better prevent terrorist attacks.

Once again, each orchestration would lead to different public value outcomes which are shaped by the techno-institutional configuration choices emerging from each service delivery configuration.

The second case we have discussed concerns the booking of medical appointments. The booking service of medical appointments offers great value, but also threats that must be managed, so that all the

\footnotetext{
${ }^{30}$ From an interview to a manager of the Digital Transformation team.

${ }^{31}$ From an interview to a manager of the Digital Transformation team.
}

\footnotetext{
${ }^{28}$ From an interview to a manager of the AgID.

${ }^{29}$ http://opentransport.mit.gov.it/
} 
involved values are preserved and properly orchestrated. The healthcare ecosystem makes APIs to book appointments in public and private hospitals available for the the developement of a booking application for medical appointments.

"The application shows the availability of appointment slots in all public and the private hospitals, in real-time. Before showing the availability of all the hospitals, the app will identify the citizen through the SPID platform which is integrated into the app; then, the app will check if he/she has an insurance, and, finally, it will display the prices for each appointment option." 32

All the private and public medical services represent different modules, and, thanks to this application, public administration can deliver public value, because citizens can choose the medical check that better suits their needs and expectations. This system might provide support to the immediate implementation of new policies from the Ministry of Healthcare, to match changes in the citizens' expectations. The Ministry can, for example, decide to reduce the waiting list for medical treatments in public hospitals by relying on the resources private hospitals offer. In order to do so, the system will have to modify the regulation and the boundary resources of the healthcare ecosystem, to allow citizens to access the medical service of a private hospital for free. This might be regulated, so that citizens will have access to services offered by private hospitals only after having completed an online health assessment to evaluate their real need for the medical service and the effective lack of availability in public hospitals for the treatment they need.

However, this service configuration can impact negatively on public expenditure, which represents a critical value for society. In fact, if private hospitals can access real-time data of a public hospital waiting list, they can dynamically change prices to make the government pay more for the most needed services.

"If, for example, the Ministry of Health sees that its data are misused by other public agencies or companies, it will promptly close or limit the access of that API to avoid negative consequences for citizens". ${ }^{33}$

To effectively create public value, it is not sufficient to consider how the interdependent services trade-off. It is also necessary to pay attention to how third parties exploit the offered services. The public service production configuration should avoid negative outcomes for the society that emerge from third parties' use of public services offered by the GaaP configuration.

The discussion of the two examples reveals the following lessons learnt and policy implications:

- The GaaP configuration is an enabler of public value creation;

- To effectively deliver public value the GaaP configuration must be appropriately orchestrated, and the different service delivery mechanisms adequately configured;

- The GaaP configuration provides the resources to orchestrate different public services configuration needed to deliver the public value citizens expects;

- The GaaP configuration improves the coordination within the public administration needed to offer more public services to meet multiple citizens' needs;

- A change in one public service provision policy might impact on the value delivered by other public service;

- In order to create public value public agencies need to orchestrate the contributions of private and public actors to meet different expectations and needs;

- The GaaP configuration must be properly orchestrated to avoid negative effect arising from third parties' exploitation of the services

\footnotetext{
${ }^{32}$ From an interview to a Member of Parliament.

${ }^{33}$ From an interview to a Member of Parliament.
}

offered by the GaaP;

- Without an effective orchestration, GaaP risks to negatively impact on the creation of public value.

\section{Conclusions}

The literature (O'Reilly, 2011; Brown et al., 2017; Janssen \& Estevez, 2013) has discussed how the adoption of the platform organisational model can help public administration to be more efficient. The platform organisation improves the efficiency of public services, because it decreases silos and duplications of core services, and facilitates the evolvability of public services (Brown et al., 2017; Janssen \& Estevez, 2013). Moreover, the platform organisation facilitates the exploitation of interdependences among different service provisions to improve or offer additional options for public services (Linders, 2012). The GaaP configuration facilitates the coordination among public agencies, public administration can offer more value to citizens, without investing additional resources (Linders, 2012; Margetts \& Dunleavy, 2013). However, from a pubic value perspective, the GaaP configuration redefines the operational capability of public administration and hence the organisational configuration and capacity which is used to create and deliver public services adn hence public value (Benington \& Mark Moore, 2010; Cordella \& Bonina, 2012). Overall, the interdependences that are created among the platforms and ecosystems increase the ability of public administration to offer services that respond better to citizens' needs and expectations and enhance the public value that is created. Nevertheless, the same interdependences can also constrain public value creation. Public agencies might create services that serve some values and negatively impact the ones served by other public agencies.

In fact, there can be a trade-off among the value different public services create when produced and provided using a GaaP configuration. The paper discussed the reasons why these trades-off emerge and addresses the problem of how to mitigate these cross effects among public services that can negatively impact public value creation.

Orchestration is identified as the governance mechanisms that continuously shape the GaaP technological and institutional configuration to maintain the needed balance among the values generated by the different public services so that the overall creation of public value is guaranteed.

The Italian case study provides insights on how the GaaP configuration enables public administration to adapt and evolve the production of public services to meet citizens' needs and expectations constantly. The creation of ecosystems for each policy domain enables public agencies to orchestrate the contributions of private and public actors and deliver the public value citizens expect.

The case also reveals that the adoption of a platform organisation is not enough to deliver public value. Public administration also requires a new mechanism of governance (i.e., orchestration) to support different service production processes simultaneously (Cordella \& Paletti, 2018), to select the most suitable production configuration for each public service, and thus to create public value (Cordella et al., 2018).

The discussion of two cases of the Italian GaaP initiative with the relevant stakeholders reveal that the generativity of the different ecosystems is a great resource, but, once again, the generativity process must be overseen and properly orchestrated ex-ante and ex-post to guarantee effective creation and delivery of public value. As Loreau, Mouquet, and Holt (2003) discussed, ecosystems are not silos. In addition, there are cross-effects and path-dependencies that go beyond the boundaries of each ecosystem. Therefore, the orchestration of public value is needed to coordinate the different ecosystems, considering how the production configuration of one ecosystem can impact the other different ecosystems (Loreau et al., 2003). The discussion of the two cases also offers a set of lessons learnt and policy implications that can help to better plan and manage the design and deployment of GaaP configuration that aim at creating public value better. 


\section{References}

Aaltonen, A., \& Lanzara, G. F. (2015). Building governance capability in online social production: Insights from Wikipedia. Organization Studies, 36(12), 1649-1673. https://doi.org/10.1177/0170840615584459.

Alford, J., \& Hughes, O. (2008). Public value pragmatism as the next phase of public management. The American Review of Public Administration, 38(2), 130-148. https:// doi.org/10.1177/0275074008314203.

Alford, J., \& O’Flynn, J. (2009). Making sense of public value: Concepts, critiques and emergent meanings. International Journal of Public Administration, 32(3-4), 171-191. https://doi.org/10.1080/01900690902732731.

Baldwin, C. Y., \& Jason Woodard, C. (2008). The architecture of platforms: A unified view. Working Papers - Harvard Business School Division of Research, 1-31. http:// search.ebscohost.com/login.aspx?direct $=$ true $\& \mathrm{db}=\mathrm{bth} \& \mathrm{AN}=43456319 \&$ site $=$ ehost-live.

Bannister, F., \& Connolly, R. (2014). ICT, public values and transformative government: A framework and programme for research. Government Information Quarterly, 31(1), 119-128. https://doi.org/10.1016/j.giq.2013.06.002.

Benbasat, I., Goldstein, D. K., \& Mead, M. (1987). The case research strategy in studies of information systems. MIS Quarterly.. https://doi.org/10.2307/248684.

Benington, J. (2007). From private choice to public value.

Benington, J., \& Mark Moore, H. (2010). Public value: Theory and practice. Palgrave Macmillan.

Boudreau, K., \& Lakhani, K. (2009). How to manage outside innovation. MIT Sloan Management Review, 50(4), 68-77. http://kevinboudreau.com/PAPEROpen Markets or Communities.pdf\%5Cnsloanreview.mit.edu.

Boyatzis, R. E. (1998). Transforming qualitative information: Thematic analysis and code development. Sage.

Braun, V., \& Clarke, V. (2006). Using thematic analysis in psychology. Qualitative Research in Psychology, 3(2), 77-101. https://doi.org/10.1191/1478088706qp063oa.

Broussine, M. (2003). Public Leadership. In T. Bovarid, \& E. L"offler (Eds.). Public management and governance. London: Routledge.

Brown, A., Fishenden, J., Thompson, M., \& Venters, W. (2017). Appraising the impact and role of platform models and government as a platform (GaaP) in UK government public service reform: Towards a platform assessment framework (PAF). Government Information Quarterly, 34(2), 167-182. https://doi.org/10.1016/j.giq.2017.03.003.

Bryson, J. M., Crosby, B. C., \& Bloomberg, L. (2014). Public value governance: Moving beyond traditional public administration and the new public management. Public Administration Review, 74(4), 445-456. https://doi.org/10.1111/puar.12238.

Carter, N., Bryant-Lukosius, D., DiCenso, A., Blythe, J., \& Neville, A. J. (2014). The use of triangulation in qualitative research. Oncology Nursing Forum, 41(5), 545-547. https://doi.org/10.1188/14.ONF.545-547.

Ciborra, C. (1996). The platform organization: Recombining strategies, structures, and surprises. Organization Science, 7(2), 103-118.

Cordella, A., \& Bonina, C. M. (2012). A public value perspective for ICT enabled public sector reforms: A theoretical reflection. Government Information Quarterly, 29(4), 512-520. https://doi.org/10.1016/j.giq.2012.03.004.

Cordella, A., \& Contini, F. (2012). Socio technical regimes and E-government deployment: The case of the Italian judiciary. ECIS.

Cordella, A., \& Iannacci, F. (2010). Information systems in the public sector: The e-government enactment framework. The Journal of Strategic Information Systems, 19(1), 52-66. https://doi.org/10.1016/j.jsis.2010.01.001.

Cordella, A., \& Paletti, A. (2018). ICTs and value creation in public sector: Manufacturing logic vs service logic. Information Polity, 23(2), https://doi.org/10.3233/IP-170061.

Cordella, A., Paletti, A., \& Shaikh, M. (2018). Renegotiating public value with co-production. Creating and capturing value through crowdsourcing. Vol. 1Oxford,UK: Oxford University Presshttps://doi.org/10.1093/oso/9780198816225.003.0008.

Cordella, A., \& Willcocks, L. (2010). Outsourcing, bureaucracy and public value: Reappraising the notion of the "Contract State". Government Information Quarterly, 27(1), 82-88. https://doi.org/10.1016/j.giq.2009.08.004.

Crabtree, B., \& Miller, W. (1999). A template approach to text analysis: Developing and using. In B. Crabtree, \& W. Miller (Eds.). Doing qualitative research (pp. 163-177). Newbury Park, CA: Sage.

Cusumano, M., \& Gawer, A. (2002). The elements of platform leadership. MIT Sloan Management Review, 31(1), 51-59. https://doi.org/10.1109/EMR.2003.1201437.

Dahl, A., \& Soss, J. (2014). Neoliberalism for the common good? Public value governance and the downsizing of democracy. Public Administration Review, 74(4), 496-504. https://doi.org/10.1111/puar.12191.

De Bruijin, H., \& Dicke, W. (2006). Strategies for safeguarding public values in liberalized utilitiy sectors. Public Administration, 84(3), 717-735. https://doi.org/10.1111/j. 1467-9299.2006.00609.x.

De Jong, J., Douglas, S., Sicilia, M., Radnor, Z., Noordegraaf, M., \& Debus, P. (2017). Instruments of value: Using the analytic tools of public value theory in teaching and practice. Public Management Review, 19(5), 605-620. https://doi.org/10.1080/ 14719037.2016.1192162.

De Reuver, M., Sørensen, C., \& Basole, R. C. (2018). The digital platform: A research agenda. Journal of Information Technology, 33(2), 124-135. https://doi.org/10.1057/ s41265-016-0033-3.

Eaton, B., Elaluf-Calderwood, S., Sørensen, C., \& Yoo, Y. (2015). Distributed tuning of boundary resources: The case of Apple's IOS service system. MIS Quarterly.. https:// doi.org/10.25300/MISQ/2015/39.1.10.

Eisenmann, T., Parker, G., \& Van Alstyne, M. W. (2006). Strategies for two- sided markets. Harvard Business Review. https://doi.org/10.1007/s00199-006-0114-6.

Fereday, J., \& Muir-Cochrane, E. (2006). Demonstrating rigor using thematic analysis: A hybrid approach of inductive and deductive coding and theme development.
International Journal of Qualitative Methods, 5(1), 80-92.

Fishenden, J., \& Thompson, M. (2013). Digital government, open architecture, and innovation: Why public sector it will never be the same again. Journal of Public Administration Research and Theory, 23(4), 977-1004. https://doi.org/10.1093/ jopart/mus022.

Gawer, A., \& Cusumano, M. A. (2002). Platform leadership: How Intel, Microsoft, and Cisco drive industry innovation. Boston, MA: Harvard Business School Press.

Ghazawneh, A., \& Henfridsson, O. (2010). Governing third-party development through platform boundary resources. 31st International Conference on Information Systems (pp. 48).

Ghazawneh, A., \& Henfridsson, O. (2012). Balancing platform control and external con tribution in third-party development: The boundary resources model. Information Systems Journal, 23(2), 173-192. https://doi.org/10.1111/j.1365-2575.2012. 00406.x.

Glaser, B. G., \& Strauss, A. L. (1965). Discovery of substantive theory: A basic strategy underlying qualitative research. American Behavioral Scientist, 8(6), 5-12.

Haas, D. F., \& Kraft, D. H. (1984). Experimental and quasi-experimental designs for research in information science. Information Processing \& Management, 20(1-2), 229-237. https://doi.org/10.1016/0306-4573(84)90053-0.

Hanseth, O., \& Lyytinen, K. (2004). Theorizing about the design of information infrastructures : Design kernel theories and principles. Sprouts: Working Papers on Information Environments, Systems and Organizations. https://doi.org/10.2752/ 146069206789377159.

Hanseth, O., \& Lyytinen, K. (2010). Design theory for dynamic complexity in information infrastructures: The case of building internet. Journal of Information Technology, 25(1), 1-19. https://doi.org/10.1057/jit.2009.19.

Hartley, J., Alford, J., Knies, E., \& Douglas, S. (2017). Towards an empirical research agenda for public value theory. Public Management Review, 19(5), 670-685. https:// doi.org/10.1080/14719037.2016.1192166.

Henfridsson, O., \& Bygstad, B. (2013). The generative mechanisms of digital infrastructure evolution. MIS Quarterly.. https://doi.org/10.25300/MISQ/2013/37.3.11.

Hudson, L. A., \& Ozanne, J. L. (1988). Alternative ways of seeking knowledge in consumer research. Journal of Consumer Research, 14(4), 508. https://doi.org/10.1086/ 209132.

Janssen, M., Charalabidis, Y., \& Zuiderwijk, A. (2012). Benefits, adoption barriers and myths of open data and open government. Information Systems Management, 29(4), 258-268. https://doi.org/10.1080/10580530.2012.716740.

Janssen, M., \& Estevez, E. (2013). Lean government and platform-based governance-Doing more with less. Government Information Quarterly, 30(January), S1-S8. https://doi.org/10.1016/j.giq.2012.11.003.

Kallinikos, J. (2011). Bureaucracy under siege: On information, collaboration and networks. In S. R. Clegg, M. Harris, \& H. Höpfl (Eds.). Managing modernity: Beyond bureaucracy? (pp. 132-154). Oxford,UK: Oxford University Press. http://eprints.lse.ac. uk/54863/.

Kallinikos, J., \& Tempini, N. (2014). Patient data as medical facts: Social media practices as a foundation for medical knowledge creation. Information Systems Research. https://doi.org/10.1287/isre.2014.0544.

Katz, M. L., \& Shapiro, C. (1994). Systems competition and network effects. Journal of Economic Perspectives, 8(2), 93-115. https://doi.org/10.1257/jep.8.2.93.

Linders, D. (2012). From E-government to we-government: Defining a typology for citizen coproduction in the age of social media. Government Information Quarterly, 29(4), 446-454. https://doi.org/10.1016/j.giq.2012.06.003.

Loreau, M., Mouquet, N., \& Holt, R. D. (2003). Meta-ecosystems: A theoretical framework for a spatial ecosystem ecology. Ecology Letters, 6(8), 673-679. https://doi.org/10. 1046/j.1461-0248.2003.00483.x.

Malone, T. W., \& Crowston, K. (1994). The interdisciplinary study of coordination. ACM Computing Surveys, 26(1), 87-119. https://doi.org/10.1145/174666.174668.

Margetts, H., \& Dunleavy, P. (2013). The second wave of digital-era governance: A quasiparadigm for government on the web. Philosophical Transactions of the Royal Society A: Mathematical, Physical and Engineering Sciences, 371, 20120382. https://doi.org/10. 1098/rsta.2012.0382.

McBride, K., Aavik, G., Toots, M., Kalvet, T., \& Krimmer, R. (2019). How does open government data driven co-creation occur? six factors and a "Perfect Storm"; insights from Chicago's food inspection forecasting model. Government Information Quarterly, 36(1), 88-97. https://doi.org/10.1016/j.giq.2018.11.006.

Moore, M. (1995). Creating public value: Strategic management in government. Harvard University Press.

Moore, M., \& Khagram, S. (2004). On creating public value corporate social responsibility initiative. 3. https://sites.hks.harvard.edu/m-rcbg/CSRI/publications/workingpaper 3_moore_khagram.pdf.

Morrell, K. (2009). Governance and the public good. Public Administration, 87(3), 538-556. https://doi.org/10.1111/j.1467-9299.2009.01756.x.

Nitesh, B., Janssen, M., van Wijk, R., de Winne, N., van der Voort, H., Hulstijn, J., \& Tan, Y. (2013). Tapping into existing information flows: The transformation to compliance by design in business-to-government information exchange. Government Information Quarterly, 30(January), S9-18. https://doi.org/10.1016/j.giq.2012.08.006.

Olleros, X. (2008). The lean core in digital platforms. Technovation, 28(5), 266-276.

O'Reilly, T. (2011). Government as a platform. Innovation, MIT Press, 6(1), 13-40.

Page, S. B., Stone, M. M., Bryson, J. M., \& Crosby, B. C. (2015). Public value creation by cross-sector collaborations: A framework and challenges of assessment. Public Administration, 93(3), 715-732. https://doi.org/10.1111/padm.12161.

Queiroz, M., Tallon, P. P., Sharma, R., \& Coltman, T. (2018). The role of IT application orchestration capability in improving agility and performance. The Journal of Strategic Information Systems, 27(1), 4-21. https://doi.org/10.1016/j.jsis.2017.10.002.

Raymond, E. (2005). The cathedral and the bazaar. Knowledge, Technology \& Policy 12, 2(3), 23-49. https://doi.org/10.1007/s12130-999-1026-0. 
Reynaers, A.-M. (2014). Public values in public-private partnerships. Public Administration Review, 74(1), 41-50. https://doi.org/10.1111/puar.12137.

Sanchez, R., \& Mahoney, J. T. (1996). Modularity, flexibility, and knowledge management in product and organization design. Strategic Management Journal, 17(S2), 63-76. https://doi.org/10.1002/smj.4250171107\%5Cnhttp://search.ebscohost. com/login.aspx direct $=$ true $\& d b=$ bth $\& A N=12493195 \&$ site $=$ ehost-live.

Sayogo, D. S., \& Pardo, T. A. (2013). Exploring the determinants of scientific data sharing: Understanding the motivation to publish Research data. Government Information Quarterly, 30(January), S19-S31. https://doi.org/10.1016/j.giq.2012.06.011.

Sieber, R. E., \& Johnson, P. A. (2015). Civic open data at a crossroads: Dominant models and current challenges. Government Information Quarterly, 32(3), 308-315. https:// doi.org/10.1016/j.giq.2015.05.003.

Stoker, G. (2006). Public value management: A new narrative for networked governance? The American Review of Public Administration, 36(1), 41-57. https://doi.org/10.1177/ 0275074005282583.

Strauss, L. (1962). The science of the concrete. The Savage Mind.. https://doi.org/10. 1007/BF01248674.

Tiwana, A., Konsynski, B., \& Bush, A. A. (2010). Platform evolution: Coevolution of platform architecture, governance, and environmental dynamics. Information Systems Research, 21(4), 675-687. https://doi.org/10.1287/isre.1100.0323.

Trochim, W. M. K. (1989). Outcome pattern matching and program theory. Evaluation and Program Planning, 12(4), 355-366. https://doi.org/10.1016/0149-7189(89)90052-9.

Ulrich, K. (1995). The role of product architecture in the manufacturing firm. Research Policy, 24(3), 419-440.

Walravens, N., \& Ballon, P. (2013). Platform business models for smart cities: From control and value to governance and public value. IEEE Communications Magazine. https://doi.org/10.1109/MCOM.2013.6525598.
Weick, K. E. (1993). The collapse of sensemaking in organizations: The Mann Gulch Disaster. Administrative Science Quarterly.. https://doi.org/10.2307/2393339.

Williams, B. N., Kang, S.-C., \& Johnson, J. (2016). (Co)-contamination as the dark side of co-production: Public value failures in co-production processes. Public Management Review, 18(5), 692-717. https://doi.org/10.1080/14719037.2015.1111660.

Yin, R. K. (1994). Case study research: Design and methods (Fourth ed.). London: SAGE Publications, Inc 29 Dec. 2008.

Yoo, Y., Henfridsson, O., \& Lyytinen, K. (2010). Research commentary -The new organizing logic of digital innovation: An agenda for information systems research. Information Systems Research, 21(4), 724-735. https://doi.org/10.1287/isre.1100. 0322 .

Zammuto, R. F., Griffith, T. L., Majchrzak, A., Dougherty, D. J., \& Faraj, S. (2007). Information technology and the changing fabric of organization. Organization Science, 18(5), 749-762. https://doi.org/10.1287/orsc.1070.0307.

Zuboff, S., \& Maxmin, J. (2002). The support economy: Why corporations are failing individuals and the next episode of capitalism. Penguin New edition (3 Jun. 2004).

Antonio Cordella is an Associate Professor in Management at the London School of Economics and Political Science (LSE), and a visiting professor at the Maastricht Graduate School of Governance, UNMERIT, The Netherland. His research interests cover the areas of E-government, Economic Theories of Information Systems, and the Social Studies of Information Systems. His publications address problems related to the adoption of ICTs in the public sector and discuss the institutional and organisational implication of such adoptions. An Italian national, he holds a $\mathrm{PhD}$ in Information Systems from Gothenburg University, Sweden. 